\title{
PRENSA E IMAGINARIO NACIONAL: LA MISIÓN SOCIAL DE LOS ACTORES SUBALTERNOS REGIONALES DURANTE LA GUERRA DEL PACÍFICO*
}

\author{
PRESS AND NATIONAL IMAGINARY: THE SOCIAL MISSION OF REGIONAL \\ SUBALTERN ACTORS DURING THE WAR OF THE PACIFIC
}

\author{
Mauricio Rubilar Luengo ${ }^{* *}$
}

\begin{abstract}
La(s) mirada(s) en torno a la Guerra del Pacífico (1879-1883) se ha enriquecido en los últimos años con nuevas temáticas, actores, problemas, enfoques y fuentes de la mano de la historia cultural y social. De esta manera se ha logrado ampliar la concepción de la guerra, la variedad de sus actores y el marco temporal de análisis, contribuyendo a la comprensión del fenómeno de la construcción histórica de las identidades nacionales en una coyuntura bélica. Este artículo busca contribuir al fortalecimiento de este enfoque mediante el análisis del discurso que formuló la prensa católica de la provincia de Concepción (Chile) acerca del papel de las mujeres y los sectores populares mediante la caracterización de las acciones de movilización ciudadana que involucraron a los grupos subalternos regionales durante los años de la Guerra del Pacífico. Intentaremos establecer la construcción de un imaginario social con proyección nacional mediante un discurso político y doctrinario de la prensa regional que buscó orientar y condicionar el comportamiento y el compromiso patriótico de determinados sectores de la sociedad chilena. Finalmente, se buscará caracterizar las acciones de resistencia de estos grupos subalternos frente al discurso y accionar hegemónico.
\end{abstract}

Palabra claves: Guerra del Pacífico, actores subalternos, prensa regional, imaginario social.

The glance around the war of the Pacific (1879-1883) has been enriched in recent years with new themes, actors, issues, approaches and sources of the hand of the cultural and social history. In this way have been extending the conception of the war, the variety of its actors and the timeframe of analysis, contributing to the understanding of the phenomenon of the historical construction of national identities in a war situation. This article seeks to contribute to the strengthening of this approach by analyzing the speech that made the Catholic press in the province of Concepcion (Chile) to Catholic women and the popular sectors through the characterization of the actions of citizen mobilization involving the regional subaltern sectors during the years of the war of the Pacific. We will try to establish the construction of an imaginary social with national projection through a political discourse and doctrinaire of the regional press which sought to guide and influence the behavior and patriotic commitment of certain sectors of Chilean society. Finally, it will seek to characterize the actions of resistance of the subaltern sectors against the hegemonic discourse.

Key words: Pacific War, subaltern actors, regional press, social imaginary.

\section{Introducción}

La historiografía en torno a la Guerra del Pacífico (1879-1883) se ha enriquecido en las últimas décadas con nuevas temáticas, fuentes, problemas, enfoques y actores de la mano de la historia cultural y social. Al intentar comprender la guerra como un problema histórico más complejo, en la medida que también incorpora dinámicas sociales y culturales, se ha logrado una ampliación en la concepción de la guerra y sus múltiples efectos. Su estudio en clave sociocultural permite cambiar el foco de análisis tanto de los fenómenos del frente interno (sociedad civil y guerra) como del frente externo (la historia de las relaciones internacionales en contraposición a la historia diplomática tradicional). Por consiguiente, esta nueva historiografía ha contribuido a la comprensión del fenómeno de la construcción nacional de las identidades colectivas de los tres países involucrados en la guerra.

La amplia historiografía relativa a la Guerra del Pacífico, tanto la de nuevo cuño como la más clásica, no ha escapado a los peligros de exponer visiones parciales con la clara intencionalidad de entregar una visión de la historia con carácter reivindicativo, exculpatorio o acusador con un notorio componente nacionalista. Esto ha sido muy propio en la historiografía de los países involucrados en el conflicto. El episodio bélico como tal involucra intensas pasiones, así como posiciones muchas veces

\footnotetext{
* Resultado del proyecto FONDECYT de Iniciación No 11121577.

** Universidad Católica de la Santísima Concepción, Departamento Historia y Geografía. Concecpción, Chile. Correo electrónico: rubilarm@ucsc.cl
} 
muy enfrentadas que se reflejan en los discursos históricos (Mc Evoy 2011). En Chile en la práctica no ha habido revisionismo historiográfico en torno a la guerra. "Se le podrá dar más peso a razones estratégicas o económicas, se podrá decir que hay que evitar un recuerdo que menoscabe a los países vecinos, pero de su legitimidad no ha dudado jamás el Chile político y cultural" (Fermandois 2005: 36).

La evolución de los temas y enfoques acerca de la guerra desde el ámbito político-militar más tradicional al más extenso de los estudios de guerra y sociedad le debe mucho a los trabajos del historiador estadounidense William Sater, en especial con su obra relativa a la construcción de la imagen heroica de Arturo Prat (Sater 2005) y sus investigaciones posteriores en donde amplió las temáticas en torno a la Guerra del Pacífico (Sater 1986, 2007). En la historiografía chilena de las últimas décadas se debe destacar el trabajo pionero de Sergio Rodríguez (1985) en torno a las problemáticas que afectaron al soldado durante la guerra, ampliando la mirada de lo militar. Respecto de los orígenes del conflicto es necesario mencionar el trabajo de Ortega (1984) que enfatiza la incidencia de variables económicas y sociales en la gestación de la guerra. De igual manera el libro de Ravest (1983) que explora los intereses empresariales y políticos en el estallido del conflicto. Desde la perspectiva social hay que destacar los trabajos de Pinto $(1993,1998)$ y Pinto, Valdivia y Artaza (2003) en torno a la construcción de la identidad pampina en el contexto de la guerra. Rodríguez (2001) y Aravena (2004) exploran en sus respectivos estudios la problemática del reclutamiento militar en el mundo rural chileno. En tanto, Carlos Méndez $(2004,2009,2013)$ ha profundizado el estudio de la problemática social de los veteranos de guerra tanto de Chile, Perú y Bolivia. En la misma línea debe consignarse el trabajo de Donoso y Couyoumdjian (2006), que estudia la evolución de soldado orgulloso a veterano indigente.

Los nuevos actores de la guerra están representados en los trabajos de Cáceres (2003), Rojas (2010), Toro (2011), Hodge y Véliz (2011) con el estudio del papel de los niños y jóvenes en el conflicto. En este sentido, es importante mencionar el novedoso trabajo de David Home (2007) en torno a la protección social de los huérfanos de la guerra. El estudio del frente comunicacional de la guerra se ha ampliado con los trabajos de Rubilar (2011, 2012), Arellano (2012) e Ibarra (2013). De igual manera, Paz Larraín $(2000,2006)$ ha dedicado su atención al rol de la mujer chilena en la Guerra del Pacífico. El estudio del frente externo de la guerra de la mano de la historia de las relaciones internacionales está representado por los trabajos de Tapia (2009) y Rubilar (2004, 2005, 2012), donde exploran las características y problemáticas que debió enfrentar la política exterior chilena en el ámbito regional en el contexto del conflicto.

En esta breve síntesis historiográfica debemos destacar tres obras colectivas publicadas en Chile que han significado un relevante aporte para el objetivo de ampliar la mirada de la guerra. En primer lugar la obra colectiva chileno-peruana liderada por Cavieres y Aljovín (2005) que busca hacer una reflexión en conjunto y comparativa acerca de las historias nacionales de Chile y Perú con especial énfasis en la Guerra del Pacífico y sus múltiples significados. En segundo lugar, el libro editado por Cid y San Francisco (2009), el que presenta varios estudios monográficos que tienen como eje de análisis el fenómeno del nacionalismo y la identidad en el Chile del siglo XIX, en especial durante la Guerra del Pacífico. El último texto es la obra colectiva editada por Donoso y Serrano (2011) que reúne catorce trabajos que incorporan nuevas perspectivas de análisis en el estudio del conflicto del Pacífico, girando en torno a tres temáticas generales: guerra, prensa y sociedad; el rigor del conflicto y estrategia y diplomacia.

Desde la historiografía peruana es necesario mencionar los aportes pioneros de Heraclio Bonilla $(1974,1980)$ y el trabajo de Nelson Manrique (1981) donde relaciona el problema nacional peruano con las guerrillas indígenas en la guerra con Chile. El estudio del frente interno peruano ha sido abordado por Guerra $(1991,2004)$ en trabajos respecto de la ocupación de Lima y el papel de la burguesía peruana. En los últimos años el historiador José Chaupis $(2007,2010)$ ha encabezado una obra colectiva que reúne el trabajo de destacados historiadores peruanos con el objetivo de ampliar la mirada de la guerra y discutir el "gran paradigma de la historia peruana". Finalmente, es imprescindible destacar el importante aporte de la historiadora de origen peruano radicada en los Estados Unidos, Carmen McEvoy. Su extensa labor investigativa (McEvoy, 2000, 2006, 2007, 2009, 2010, 2011) se ha centrado en el estudio del discurso católico nacionalista chileno, la retórica y el ritual en la guerra y los fenómenos socioculturales durante la Guerra del Pacífico y que ha sintetizado en su relevante obra Guerreros Civilizadores. 
Por consiguiente, el presente artículo busca contribuir al fortalecimiento de este enfoque socio-cultural mediante el análisis del discurso que formuló la prensa católica de la provincia de Concepción referente al papel de las mujeres y los sectores populares y caracterizar las acciones de "movilización" ciudadana de los sectores subalternos de la provincia durante los años de la Guerra del Pacífico. El estudio de la prensa regional como actor social y expresión de la opinión pública nos permite conocer la construcción de un imaginario social con proyección nacional mediante un discurso político y doctrinario que buscó orientar y condicionar el comportamiento y el compromiso "patriótico" de determinados sectores de la sociedad chilena. De igual manera se buscará caracterizar algunas acciones de resistencia de los sectores subalternos frente al discurso y accionar hegemónico. Las fuentes que se estudiarán se vinculan con la prensa de la ciudad de Concepción y Chillán del período 1879-1881.

\section{Prensa y la problemática opinión pública chilena en la segunda mitad del siglo XIX}

En la segunda mitad del siglo XIX comenzó a configurarse en Chile el periodismo liberal moderno, el que tuvo como expresión orgánica la empresa periodística, ya que cada día ganó más terreno la información de los comentarios y las polémicas de carácter meramente doctrinario (Santa Cruz 2010). En definitiva, "la prensa liberal se define a sí misma por su pretensión informativa y, consecuente con ello, por la generación de un mercado noticioso y de empresas suficientemente capaces para competir en él y desarrollarlo" (Santa Cruz 1998: 11). Resulta, por tanto, de interés abordar la prensa como un "actor" de relevancia y no un mero "testigo" de los acontecimientos que marcaron la coyuntura trascendental que significó la Guerra del Pacífico y su impacto mediático. La condición de actor sociocultural de la prensa debe ser entendida desde sus propias instalaciones ideológicas y culturales, construyendo y difundiendo sentidos acerca de lo social (Santa Cruz 2010: 11), todo ello en función de su interacción con otros actores sociales (gobierno, partidos políticos, instituciones del Estado, Iglesia, movimientos sociales, etc.) por medio de la publicación de información y principalmente en la elaboración de un discurso (línea editorial) que buscó generar una opinión, un debate e influir en otros actores sociales (Rubilar 2011).
El concepto moderno de opinión pública hunde sus raíces en los cambios culturales de los siglos XVII y XVIII, específicamente cuando la intelectualidad europea apeló a la razón para el análisis crítico del Antiguo Régimen (Fernández 2003), (Cruz 2003). De acuerdo con Cabrera y Berbesí (2006: 521), los espacios públicos surgen y actúan sustraídos de las imposiciones del Estado, "discurriendo en nuevas ideas y conceptos, que incluyen precisamente los cuestionamientos y los replanteamientos sobre las relaciones sociales y el concepto de Estado". Para Habermas (1986: 124), el surgimiento de la opinión pública como fenómeno sociopolítico (de corte burgués) ha de buscarse en la transición del Antiguo Régimen hacia la Modernidad. La opinión pública o general -entendida como una postura reflexiva, razonada y discutida abiertamente respecto de los asuntos públicos- surgió en Occidente como consecuencia de las transformaciones políticas y sociales a finales del siglo XVIII. En el área hispanoamericana la conformación progresiva de una opinión pública nació de la fractura política y cultural que significó el tránsito del Estado monárquico (antiguo régimen) al republicano de corte liberal y de las discusiones políticas que pretendían solucionar el problema de la soberanía y la representación.

En las primeras décadas del siglo XIX una nueva concepción del Estado, la nación, la soberanía y las instituciones, definió las luchas entre un imaginario de corte antiguo y los nuevos referentes modernos, que encuentran asidero en la palabra pública y privada. Para Guerra (1992) este es el momento de la fractura de la unidad moral de la monarquía hispánica y, en consecuencia, allí se gesta el surgimiento de las futuras naciones y de la futura opinión pública de los nuevos Estados. Una vez establecidas las élites republicanas en el gobierno, se buscó la conformación de una opinión pública en correspondencia con el orden recién establecido (González 2003). Esta opinión pública será orientada por tres medios: la prensa, la escuela y las ceremonias, en los nuevos valores de la ciudadanía, la representación política y las libertades individuales, lo que establece un claro deslinde entre lo público y lo privado (Guerra y Lemperiere 1998).

El siglo XIX en Hispanoamérica mostró el fortalecimiento de lo "público" de la mano de una gradual y mayor participación política, de la ampliación del sistema educacional y el nacimiento de nuevos actores políticos y sociales. El fenómeno de la opinión pública se desarrolló a partir de la 
conformación de un espacio de discusión donde por los medios de comunicación se construyó un espacio público de intercambio y discusión de ideas, practicándose una crítica constante a las fuerzas políticas en pugna, los organismos de gobierno y el poder del Estado. En este espacio la ciudadanía (élite sociopolítica) recibía información útil (pero naturalmente mediatizada) para expresar y retroalimentar sus posturas respecto del acontecer político, estas se manifestaban, en parte, en la misma prensa, mítines, reuniones sociales, organizaciones políticoculturales y los procesos electorales periódicos. Stuven (2000: 16-17) sostiene que la "esfera de lo social configuró un campo de batalla donde se debatía con el poder público. También estableció una nueva forma de contacto entre el Estado y la sociedad. Es decir, los temas sociales y políticos fueron considerados legítimamente tareas cívicas de una sociedad comprometida en el debate público crítico". En definitiva, la configuración de una esfera pública y el ejercicio de la discusión en ella son parte de la esencia de los sistemas republicanos representativos, fenómeno que se consolidó en Latinoamérica con el triunfo del modelo sociopolítico liberal y que a partir de los años setenta del siglo XIX se materializó en una restringida pero madura y consolidada opinión pública (González 1999), (Jaksic y Serrano 2010).

En consecuencia, entenderemos por el fenómeno de la opinión pública aquella esfera distinta al poder estatal donde participan tanto individuos con cada vez mayor autonomía del Estado como grupos de interés de diversa filiación ideológica (partidos políticos, asociaciones gremiales, instituciones ligadas a credos religiosos, etc.). Su forma de divulgación principal son los medios de comunicación (prensa escrita), aunque también incluye otras formas de expresión de ideas respecto de la administración del Estado y otros temas del acontecer político, económico, social o cultural. En esta esfera se practican la discusión, la crítica, el intercambio y la retroalimentación de puntos de vista distintos acerca del acontecer de una sociedad, lo que le convierte en un ente dinámico y en transformación permanente (Rubilar 2011, 2012), (Ibarra 2013). No obstante, es necesario señalar que este espacio de discusión en el último cuarto del siglo XIX en Chile quedó circunscrito a aquel sector de la población fundamentalmente urbana que poseía un nivel de ilustración general o formal y que interactuaba socialmente en virtud de la información periodística que consumía. Socialmente abarcó al sector de la élite gobernante e intelectual, la reducida clase media formada por funcionarios públicos, profesores y profesionales liberales y parte del mundo popular representado por los artesanos urbanos, entre otros, quienes formaron parte de manera efectiva del sistema político mediante el voto (censitario) y la participación en asociaciones gremiales. El amplio mundo rural chileno quedaba excluido de este espacio de discusión pública.

\section{Los hijos del Biobío y la Guerra del Pacífico: La Iglesia y la prensa católica como impulsores del compromiso ciudadano de los actores subalternos}

El desafío que significó para Chile la Guerra del Pacífico involucró un esfuerzo que se presentó por parte de la élite gobernante e intelectual como de carácter nacional y que debía involucrar el compromiso de todos los sectores sociales. El objetivo final era el triunfo militar, la derrota de los enemigos de la República y la exaltación de la superioridad chilena. Concepción como antigua capital de la tradición militar en la guerra de Arauco y de la lucha independentista se sumó con energía a la tarea de cohesionar el esfuerzo bélico de los hijos del "País de Penco", bajo la bandera de los intereses nacionales y olvidando, momentáneamente, las disputas doctrinarias y políticas que la dividían. Al momento de estallar la guerra en 1879 Concepción y su provincia manifestaban un importante crecimiento económico y material de la mano de las riquezas agrícolas, mineras y del comercio (Pacheco 2003). Así describió a la Metrópolis del Sur el hombre de letras y diplomático colombiano José María Samper en su visita a la zona ya terminada la guerra en 1885 :

(...) en ella abundan hermosos almacenes $\mathrm{y}$ tiendas, $\mathrm{y}$ hay espaciosos $\mathrm{y}$ bien surtidos hoteles y restaurantes, es un centro mercantil de primer orden, a donde afluyen las exportaciones e importaciones que sirven a muchas provincias de centro y sur de Chile, del propio modo es un centro político, literario y social muy importante. Ejerce notoria influencia sobre muchas provincias; tiene una Corte de Apelaciones muy respetable, un gran Liceo provincial en el que se dan muy variadas enseñanzas, una Silla episcopal que goza de considerable autoridad y diarios bien servidos 
cuya publicidad da realce a las letras, al foro y a los intereses económicos ${ }^{1}$.

Paralelo a este progreso material y económico, la sociedad penquista había protagonizado desde los años setenta del siglo XIX intensas disputas ideológicas que enfrentaron a los sectores inspirados en los ideales del liberalismo doctrinario con el mundo conservador-católico. En esta etapa destacaron como importantes figuras de la política regional en el mundo liberal y radical personajes como Víctor Lamas Miranda, Ricardo Claro Cruz, Carlos Castellón Larenas, Miguel Ignacio Collao, Edmundo Larenas, entre otros. Muchos de ellos representaron a la región en el Congreso Nacional en calidad de senadores y diputados (Campos Harriet 1980).

El fortalecimiento de la sociedad civil penquista orientó su desarrollo bajo la notable pugna doctrinaria entre los principios liberales y los del mundo conservador-católico que representó con pasión admirable el obispo de Concepción, Mons. José Hipólito Salas. Su protagonismo eclesiástico y político se hizo notorio a raíz de la polémica de los cementerios que se proyectó hasta 1883 cuando se dictaron finalmente las llamadas leyes laicas por parte del gobierno de Domingo Santa María (Krebs 1981). La actitud del obispo Salas, de acuerdo con Andrés Medina (1997), se destacó por una postura de coherencia doctrinal, no conciliatoria y crítica de la actitud "confusa" de ciertos sectores del conservadurismo chileno representado por aquellos que el obispo de Concepción denominó "los católicos ilustrados de Santiago", quienes desconocían la virulencia que alcanzaba en las provincias el conflicto político-religioso y se permitían criticar al obispo Salas por su forma de enfrentarlo.

Al momento de estallar el conflicto del Pacífico, el obispo Salas se transformó en uno de los primeros dignatarios de la Iglesia chilena en formular un llamado al pueblo católico a unirse al esfuerzo bélico y apoyar desde la oración y la acción doméstica la causa nacional. Las páginas del periódico penquista La Libertad Católica fueron uno de los medios más eficaces para la socialización del pensamiento pastoral acerca del significado de la guerra, el papel de la Iglesia y el compromiso ciudadano (Casanueva 2002). En este sentido el periódico católico penquista destacó a comienzos de abril de 1879 el interesante contenido de la Carta Pastoral al clero y fieles de la Diócesis del obispo Salas de abril de 1879 -que se leyó profusamente en las misas dominicales de la diócesis y de la que se hicieron 400 copias que circularon de mano en mano entre los soldados chilenos en los campamentos militares (McEvoy 2010)-, visión que posteriormente Salas profundizó en su libro titulado El Guerrero Cristiano (1880).

El significado de la pastoral se puede dimensionar en varios niveles: en primer lugar, es una de las primeras pastorales que un obispo de la Iglesia chilena dirige a sus fieles por motivo de la guerra; tuvo un gran impacto "ideológico-doctrinario" en la construcción de la legitimidad de la guerra en virtud de la solidez intelectual de su autor; Salas expuso por primera vez la teoría del "Guerrero Cristiano", la idea de la "Guerra Justa" y la guerra como "Regeneración moral y social" en beneficio de la Patria y como castigo para los enemigos de la República chilena. Junto con ello, explicitó los deberes del "ciudadano-cristiano", tanto en el campo de batalla como en los variados ámbitos de la vida cotidiana (especial atención dedicó relativos al rol de la mujer en el frente interno). De igual manera, el obispo de Concepción planteó un tema que resultaba muy sensible para la Iglesia chilena y para él, producto de su traumática experiencia político-pastoral previa: la necesidad de que el Estado y la Iglesia mantuvieran una unidad de espíritu que contribuyera al buen manejo de los negocios públicos y en la correcta conducción de la guerra. El obispo Salas esperaba que gracias a las "súplicas" y "oraciones públicas", Dios iluminara a los "Altos Puestos" con sabiduría, prudencia, piedad, rectitud, justicia (todo aquello que desde la perspectiva de Mons. Salas le había faltado a la clase política chilena en la década de los 70 en su pugna con la Iglesia). La máxima para el obispo era "evitar sembrar la división y la discordia", meta y consigna actual "de la falange incrédula de la impiedad" que busca socavar "los cimientos del orden y hundir en una misma sima a la religión con la sociedad y a la moral con la libertad". Esto siempre ha sido, indicó Salas, "y hoy más que nunca lo es, obra satánica y maldita por Dios". En definitiva, el obispo penquista expuso a los fieles católicos y a la ciudadanía la justicia de la causa chilena, ya que el país había sido forzado a entrar en una guerra que nunca buscó y que por tanto contaba con la protección del "Dios de los Ejércitos", que lo era también de la justicia y del derecho. Al mismo tiempo, el obispo de Concepción expresó la necesidad que la sociedad en su conjunto "se eleve sobre la turbia atmósfera de las pasiones 
políticas y de las exigencias del círculo, y colocar muy alto el pabellón de la República". Finalmente, rogó para que los oficiales y soldados del Ejército de Chile, "hombres de corazón y de fe", se "batan como leones" en los campos de batalla, valientes que "en sus levantados pechos albergan la intrepidez del guerrero y la sencilla fe del cristiano". Era en definitiva la expresión de la unión de "la cruz y la espada" por la causa nacional.

La proyección social del mensaje pastoral y sus efectos en las conciencias ciudadanas mediante la formulación de un imaginario patriótico-católico quedó en evidencia en esos primeros días de la guerra en un decidor testimonio dado a conocer por el periódico La Libertad Católica del 18 de abril de 1879 y que tituló "Sublime Patriotismo". En él se hizo referencia noticiosa a la actitud de una mujer del pueblo en relación con el compromiso con la guerra y los efectos de la pastoral del obispo Salas. Es inevitable no acudir a las páginas del vocero del mundo conservador penquista:

El domingo se leyó en todas las iglesias la hermosísima Pastoral del Iltmo. Señor Obispo en que se alentaba al pueblo a contribuir de todos modos para la salvación de la patria. La cocinera de una de nuestras respetables familias, que oyó la Pastoral, de vuelta a la casa se presenta a sus patrones, diciéndoles que desde ese instante erogaba la mitad de su escaso sueldo para los gastos de la guerra y mientras dure esta. Rasgo como el que acabamos de referir es altamente conmovedor y solo lo pueden producir los hijos de nuestra querida patria. Una pobre mujer soporta con gusto la angustia de sus necesidades con tal de tener la satisfacción de contribuir con su óbolo a la salvación de nuestra honra. ¡Sublime patriotismo! ¡Benditas sean las palabras que tales efectos producen!

La apelación por parte del periódico católico al ejemplo que representaba la actitud de generoso desprendimiento de la mujer de origen popular, cocinera de una respetable familia penquista, simbolizaba la aspiración de una conducta que se debía generalizar en el colectivo social mediante una movilización activa que materializaría el imaginario social-católico que el obispo Salas con ayuda de la prensa buscó proyectar a la sociedad penquista.
Este espíritu de patriotismo y compromiso ciudadano que inundó a todas las clases sociales sin importar la condición económica es ejemplificado por La Libertad Católica al informar el 2 de mayo de 1879 que personas que trabajan en distintas actividades ofrecieron sus servicios para ir en beneficio del Ejército. Es así como se dio a conocer la labor de los sastres Domingo Contreras, Zacarías Espinoza y Lorenzo Sepúlveda que ofrecieron sus servicios para cortar gratuitamente los trajes que se van a confeccionar para la brigada de Policía, así como también M. Tatin "pondrá a disposición del cuerpo de Policía una gran cantidad de salchichones para que le sirva de alimento cuando marchen al Litoral".

Pero no solamente el mundo popular era el destinatario de las prédicas y mensajes periodísticos de movilización social. El principal baluarte para la Iglesia en la defensa de sus principios en la sociedad chilena era la mujer católica de élite en sus múltiples roles como madre, esposa e hija. En una sociedad política dominada por el elemento masculino de predominante orientación liberal y anticlerical, la mujer católica se transformó en un activo agente de resguardo de los principios católicos en el seno familiar y podía ejercer una eficaz capacidad moderadora mediante la enseñanza y el ejemplo social. En definitiva, la mujer católica fue considerada un dique de contención a la secularización y a la vez que el agente catequizador por excelencia (Serrano 2008). En virtud de ello, la Iglesia penquista buscó orientar el accionar patriótico femenino mediante una activa participación en el espacio público. En este sentido las páginas de la prensa católica penquista se constituyeron en la caja de resonancia de la acción social desarrollada por las mujeres católicas de la diócesis. Las mujeres de la élite inspiradas por las palabras del obispo Salas y bajo la dirección del deán de la catedral y director de la congregación, Domingo Benigno Cruz, rápidamente se organizaron en la Sociedad "Hijas de María" para recaudar fondos por medio de colectas, reunir material, ropa y la formación de una ambulancia de la "Purísima Concepción" para ser destinada al cuidado de los soldados heridos en el campo de batalla (La Libertad Católica, 15 y 29 de abril de 1879). Esta tarea involucraba un comportamiento ético y social acorde a las graves circunstancias por las que atravesaba la patria en peligro. Así lo expresó el periódico La Libertad Católica el 8 de abril de 1879: 
Las hijas de María por su institución declaran la guerra al lujo, verdadera plaga de la sociedad y viste con modestia, ahorra cuantiosas sumas que en este caso servirán para las necesidades de nuestro ejército y da una prueba de conocer que sienta muy mal los trajes elegantes y vistosos hoy cuando solo se exige valor y energía a los varones, abnegación a las mujeres y desprendimiento a todos.

Las páginas de La Libertad Católica en los primeros meses de la guerra dieron a conocer el trabajo de las mujeres de la sociedad penquista y los recursos aportados a la causa nacional. Como ejemplo se puede mencionar el aporte de doña Tránsito Unzueta de Urrejola que donó 100 pesos; doña Laura Molina de Prieto, 20 pesos; Josefa Zañartu de Cruz, 10 pesos; Francisca Zañartu de Río, 10 pesos; Teresa Reese, 10 pesos y congregaciones como del S. C. de Jesús, 50 pesos; Convento de San Agustín, 20 pesos; Convento de Santo Domingo, 10 pesos, entre otros. En el caso de aquellas señoras y señoritas que aportaron con su esfuerzo personal, podemos destacar a: Pilar Benavente de Manzanos, 6 camisas; Carmen Pradel Casanueva, doce pares de sábanas, cuatro colchones y ocho pares de calzoncillos; Lucrecia Marchán, 16 pares de sábanas y cuatro fundas; Ana Délano de Piummer, una pieza de tocuyo para calzoncillos y cuatro camisas y Ana Merino, 4 pares de sábanas, entre muchas otras. La Libertad Católica del 12 de abril de 1879 dio a conocer los fondos reunidos hasta ese momento por las mujeres católicas (1.102 pesos) y variados objetos y los nombres de la directiva de la Sociedad Hijas de María: Mercedes Rodríguez (viuda de Martínez), presidenta y Sara Arrau, secretaria. Este tipo de acciones de apoyo social al esfuerzo bélico dirigidas por mujeres católicas se constituyó, en el discurso periodístico católico, en el paradigma del compromiso femenino y la mejor prueba de la proyección de los principios cristianos en el accionar social de carácter patriótico.

El compromiso ciudadano, desde la perspectiva de la prensa católica, debía evitar comportamientos sociales reñidos con la gravedad del conflicto, el sacrificio de sangre chilena en los campos de batalla y sus consecuencias como la miseria y tristeza que afectaban a numerosas familias. Desde esa perspectiva, el periódico La Libertad Católica de 10 de junio de 1879 criticó ácidamente la iniciativa de la Sociedad Filarmónica de Concepción frente a la idea de desarrollar "un suntuoso baile para las familias" acomodadas de la sociedad penquista y para "la entretención de los que de cerca no tienen que sufrir los males inmediatos de la pelea".

\begin{abstract}
¡Qué triste espectáculo presentaría después la sociedad de Concepción! Mientras que nuestros hermanos sufrían los horrores del combate y morían por su patria, esto es por defender sus ciudades, sus familias y su honor, acá, los jóvenes y las bellas se entregaban a los devaneos del festín y danzaban tal vez al compás de los cañonazos y daban una vuelta de valse, siguiendo los acordes de los ayes de los moribundos.
\end{abstract}

Para el periódico católico penquista, "las grandes virtudes que enaltecen a los hombres y los caracteres $\mathrm{y}$ forma a los héroes no se adquieren ciertamente en las danzas de los salones. De allí solo sale el carácter afeminado y pusilánime que predispone o tal vez es ya un paso a ese período de decadencia porque han pasado los pueblos...". En definitiva, la verdadera condición de católico y patriota debía demostrarse en un compromiso activo de apoyo a la causa nacional y en una actitud social marcada por la prudencia y la moderación en el actuar cotidiano.

Junto con este tipo de acciones lideradas por las matronas católicas penquistas se desarrollaron en esos primeros meses de la guerra expresiones de fervor religioso-patriótico que involucraron la participación de una numerosa concurrencia y que se transformaron para el periódico católico en la ocasión de demostrar a la sociedad penquista el compromiso del mundo católico en la esfera pública. El 29 de abril de 1879 el periódico conservador invitó a sus lectores a una actividad católica y de concurrencia masiva llamada romería patriótica hacia la cruz que se encontraba a la salida de la ciudad, camino a Penco, y que se realizó el domingo 4 de mayo. El objetivo de este acto fue rogar por las necesidades de la patria: "La procesión saldrá a las 4 de la tarde de la capilla de las monjas de la Providencia. Se conducirá tres andas: en una irá la cruz, en otra Nuestra Señora del Carmen, patrona jurada de nuestro Ejército y en la tercera el Ángel San Miguel, tutelar de la milicia. Llegada la procesión al lugar de su destino se pronunciará un discurso religioso patriótico". La Libertad Católica expresó su deseo de una alta concurrencia debido a que 
"como buenos patriotas y como buenos católicos, es deber asistir y rogar a Dios por el triunfo de las armas chilenas, así como también para que mediante la oración pedirle a Dios que infunda en el soldado chileno el valor y el coraje de los héroes".

Posterior a la realización de romería patriótica La Libertad Católica informó el 6 de mayo de 1879 de una consecuencia no deseada del acto religioso y que afectó directamente a los participantes varones de la procesión. Tras concluido el acto masivo y a las afueras de la catedral, varios de los asistentes, especialmente artesanos, fueron obligados a incorporarse a los batallones cívicos por el accionar de las comisiones reclutadoras que actuaban en esos primeros meses de la guerra en las ciudades y campos chilenos. Dicho accionar fue catalogado por el periódico como "cruel y bárbaro, y no es por cierto el mejor modo de conquistarse voluntades resueltas para servir a la Patria".

El vocero periodístico del clero penquista, en editorial del 2 de mayo titulada "Actividad y Prudencia", expresó sus críticas observaciones al proceso de reclutamiento que llevaban a cabo las comisiones dispuestas por la autoridad política. Junto con señalar que dicha actividad se ejecutaba fundamentalmente en las capitales de provincia, manifestaba la necesidad que se desarrollara en forma más equitativa a nivel nacional y de acuerdo con una proporción a la población de cada localidad. Su ejecución en las capitales de provincia trae el inconveniente, desde la perspectiva del periódico, de "la paralización de las industrias, de esparcir el miedo y el temor en los ánimos del pueblo", lo que obligaba a las autoridades a "usar de rigor para hacer efectiva la conscripción" y por tanto, "el noble ardor del patriotismo queda ahogado y al entusiasmo y ardor bélico suceden el miedo y el cobarde temor". Ejemplo de los efectos del reclutamiento bajo esta modalidad en la ciudad de Concepción fue el acuartelamiento de casi la totalidad de los artesanos, "los trabajos públicos y particulares han tenido que cesar; estamos en plena estagnación de todo movimiento y ni siquiera se ve transitar por las calles a los campesinos que venden artículos de primera necesidad". Lo anterior para el editorialista se debía a que las Comisiones reclutadores, compuestas por agentes subalternos, ejecutan ciertos actos de violencia y arbitrariedad que infunden el espanto en las "gentes del pueblo". Ejemplo de ello fue lo ocurrido en la ciudad de Los Ángeles, en la que "la comisión reclutadora esperó a la puerta de la iglesia el sábado santo, día de gran concurrencia, y allí en el mismo atrio del templo o en su cercanía se comenzó a echar el guante a los que habían acudido a la fiesta religiosa y a conducirlos al cuartel" ( $\mathrm{La}$ Libertad Católica, 2 de mayo 1879).

En el caso de Concepción, las comisiones actuaron contra campesinos provenientes de otros departamentos "que vendían sus pobres efectos" en la ciudad, viéndose obligados a remitir "con algún muchacho u otra persona las carretas y sus bueyes al lugar de su procedencia”. El resultado ha sido, indica el periódico, que "ya no entra a Concepción un solo leñador ni un solo vendedor de artículos de primera necesidad; y como la industria ha cesado por falta de operarios, Concepción presenta el silencioso aspecto de una semana santa de los tiempos antiguos". Finaliza la editorial preguntándose, "¿qué se saca con alistar a quien marcha forzado a tomar el fusil?" (La Libertad Católica, 2 de mayo de 1879). La respuesta evidente se relaciona con la resistencia de parte de los sectores populares campesinos y urbanos, con la consiguiente falta de reclutas voluntarios para llenar las cuotas de los regimientos cívicos que se estaban formando para el esfuerzo bélico de carácter nacional. Lo anterior deja en evidencia uno de las problemáticas históricas más complejas en el estudio del compromiso ciudadano chileno frente a la guerra: la voluntariedad o lo forzoso en el reclutamiento de los soldados para el esfuerzo bélico.

La formación e incorporación de los ciudadanos a las unidades militares no estuvo exenta de dificultades y polémicas que la prensa dio a conocer en sus páginas. Un caso notorio fue el del Batallón Cívico de Chillán y la problemática labor de reclutamiento de ciudadanos para formar las filas de esta unidad. Tanto el periódico La Discusión de Chillán como El Ñuble de la misma ciudad, informaron de las resistidas acciones llevadas a cabo por las comisiones de reclutamiento en Chillán y en los pueblos cercanos como Coihueco, Yungay, El Carmen, San Ignacio, San Carlos, etc. Los periódicos de la época denunciaron la violencia aplicada contra algunos integrantes del bajo pueblo de origen campesino y artesanal que resistieron su incorporación a las unidades militares. Lo anterior estuvo unido a la escasez de recursos para la implementación de la instrucción y alimentación de los integrantes de los batallones, lo que llevó en julio de 1879 a algunas acciones de queja de los futuros soldados y que derivó en el desarrollo 
de un motín de algunos integrantes del Batallón Cívico de Chillán. Dicha acción llevó a la prensa de Chillán a manifestar su inquietud y desconfianza por reclutas que no responden a la "confianza de la patria" e intentan "abandonar su cuartel tres veces en una semana”. Para El Ñuble (16 de julio de 1879) frente a estos actos la conclusión era clara y muy decidora: "No olvide el gobierno la conveniencia que hay en movilizar cuanto antes al Batallón Chillán. Sabido es que el soldado fuera de su pueblo hace proezas y en su pueblo solo sabe hacer motines". En el imaginario social que buscó proyectar la prensa regional frente a la necesidad de compromiso cívico de la población de raíz popular quedaba en pie una enorme dicotomía: el valor del hombre del pueblo en su función militar (roto valiente), pero el peligro que representaba en su condición popular e indisciplinada (roto rebelde).

A pesar de estas evidentes dificultades y el rechazo que despertó el accionar de las comisiones de reclutamiento, el compromiso de la sociedad regional en el esfuerzo bélico -que la prensa fortaleció con su actividad propagandística y su orientación de la opinión pública- se materializó con el fluir constante de los hijos de la provincia de Concepción a la conformación de los batallones cívicos que se dirigieron a los campos de batalla del norte. Destacó en este sentido la formación del Batallón de Infantería Cívico Movilizado Concepción; del Batallón y posterior Regimiento de Infantería Cívico Movilizado Chillán y del Batallón Cívico Movilizado Los Ángeles, todos ellos de importante participación en las distintas campañas de la guerra. Un testimonio vívido del compromiso voluntario del bajo pueblo es el del recluta del Batallón Cívico "Chillán", Hipólito Gutiérrez, oriundo de la localidad de Colton, subdelegación de Bulnes. En su diario de campaña nos cuenta que junto a amigos y compadres se fueron a Chillán a enrolarse "a su entero gusto" para ir al norte, a Lima, "a defender la Patria hasta morir o vencer por su bandera chilena". Al momento de despedirse de sus seres queridos Gutiérrez apela a la justicia de la causa y la protección divina: "no lloren, hombres, que esperamos en Dios del que hemos de volver a nuestra tierra con vía y salud y los volvamos a ver; nadien muere mientras no se le llegue la hora ni aunque andemos dentre las balas". Finalmente el recluta Hipólito Gutiérrez retornó al seno de su familia tras el triunfo de las armas chilenas en Chorrillos y Miraflores y la toma de la capital del Perú en enero de 1881 (Quiroz y Gutiérrez 1976).
En la lógica de reforzar la idea de "comunidad nacional" tras el esfuerzo bélico, la prensa buscó destacar el compromiso voluntario de algunos grupos considerados "conflictivos" en la sociedad chilena como era el caso del mundo indígena. Un ejemplo del discurso de integración nacional fue lo informado por La Libertad Católica en su ejemplar del 15 de abril de 1879, en cuanto a la actitud "patriótica" mapuche a raíz del ofrecimiento del "cacique civilizado" Colipí de poner a disposición del gobierno chileno un escuadrón de 600 indios para sumarse a los contingentes que se enviarían al litoral norte:

\section{Si logra ir un escuadrón de esa naturaleza nos gustaría ver la cara que pondrían los cholos con el aspecto feroz de los salvajes de nuestras selvas y al terrible chivateo que precede a sus temerarios y diabólicos ata- ques. Los peruanos que decían que nuestros batallones solo estaban acostumbrados a pelear con indios, cosa que era como comer un pan, verían lo que es el araucano en las batallas, cuando empuña su lanza y las riendas de su caballo.}

De esta manera en función del contexto bélico, la prensa católica penquista reactualizó en su discurso periodístico el valor y la temeridad del pueblo araucano-mapuche como símbolo de espíritu indómito-guerrero y buscó transformar en garantía de victoria la herencia épica que se proyectaba en el mestizo-soldado (roto) que enfrentaría en el lejano territorio nortino a los enemigos de la nación chilena.

La retórica católica y el discurso periodístico de la necesidad de una mayor cohesión espiritual y social de la nación chilena tuvo en el combate naval de Iquique del 21 de mayo de 1879 el gran factor catalizador de un imaginario nacional marcado por el valor heroico y el sacrificio supremo. En editorial de 27 de mayo de 1879 La Libertad Católica dimensionó el significado cristiano del sacrificio de Prat y sus hombres: "quien así pelea, quien al morir sobre las ondas del mar o en un campo de batalla fija su vista en el cielo y ofrece a Dios su vida en cumplimiento del deber, recibe una especie de bautismo de sangre y ejecuta un acto heroico y cristiano". Concluyó el editorial con la siguiente reflexión que vuelve al eje del conflicto político-doctrinal entre liberalismo y catolicismo: "Ojalá que la noble sangre que corrió 
el 21 de mayo y la que probablemente tendrá que correr todavía apague las discordias civiles y abra los ojos a los hombres que pretenden expulsar a Dios de la familia y de la sociedad".

Con el objetivo de reforzar la idea de la intervención divina a favor de la causa chilena, La Libertad Católica en editorial titulada Te deum laudamus! (24 de junio de 1879), expresó la profunda convicción del pueblo católico en cuanto a que detrás del esfuerzo bélico no solo estaba la ciudadanía alentándolo mediante las oraciones y plegarias que eran elevadas al cielo para el triunfo de los marinos chilenos ocurrido en Punta Gruesa, sino que también era el mismo Dios quien apoyaba a Chile:

Nada más justo y racional que esa acción pública de gracias a la Providencia divina por los favores recibidos ¿Quién, sin ser ciego u obstinado, puede dejar de reconocer en la brillante victoria del 21 de Mayo la mano visible de la bondad divina que a Chile protegía? Sí; la mano de Dios se conoce en esos hechos que la inteligencia humana no ha podido prever y cuya realización desconcierta los planes mejor combinados. Entonces es cuando el hombre se ve obligado a doblar su cabeza $\mathrm{y}$ reconocer una fuerza superior.

En definitiva, la movilización de la "nación en armas" iba acompañada de la "movilización de la nación católica" tras el triunfo militar chileno y a ello contribuyó el discurso integrador de la prensa católica penquista. Ejemplo de la unión de fe y esfuerzo bélico es lo indicado por el editorial de La Libertad Católica de 9 de mayo de 1879: "el pueblo cumple en todas partes magníficamente con su deber: ha ofrecido y está ya dando su dinero, su sangre y cuanto se le pide para la defensa de la Patria". En tanto, "las autoridades obran hoy con actividad, después de haber perdido un tiempo precioso". No obstante queda un gran deber: "es el deber de la oración pública, de la súplica, que la sociedad chilena debe dirigir al Dios de los Ejércitos pidiéndole la victoria". Por consiguiente, junto con la oración privada, personal, en los hogares y en los templos, debía producirse la "oración social", la súplica dirigida públicamente al Dios Supremo a nombre de la nación. Esta era la única forma posible de garantizar la protección divina para un pueblo guerrero y cristiano como el chileno.

\section{Reflexiones finales}

La prensa regional en especial la de carácter católico-conservador manifestó en sus páginas (especialmente en sus editoriales) un discurso que buscó fortalecer un imaginario nacional marcado por la necesidad de alcanzar una "cohesión social" frente al desafío bélico y una justificación legitimadora del accionar del Estado en su lucha contra los enemigos de la República. Este discurso utilizó tempranamente una división social de funciones o roles sociales asignados a cada segmento de la sociedad, de género e incluso étnico con el único objetivo de contribuir en un esfuerzo colectivo (pero segmentado) para el triunfo de la nación en la guerra contra Perú y Bolivia. De esta manera se formuló un discurso que buscó incluir a determinados grupos como los mestizos, el bajo pueblo, e incluso los pueblos originarios en el ideario nacional que buscó consolidar la élite intelectual, política y social del Chile decimonónico. En el caso de la prensa católica representada por el periódico $L a$ Libertad Católica, expresión de los intereses del clero penquista y en especial de la visión del obispo José Hipólito Salas, expresó un discurso militante, patriótico-nacionalista y de contenido doctrinal que buscó movilizar al "pueblo católico penquista", en especial a las mujeres, para desarrollar desde el frente interno (el seno familiar, la acción social y la manifestación pública) su compromiso militante y un comportamiento social específico bajo la orientación de los principios católicos amenazados por la ofensiva liberal de la segunda mitad del siglo XIX. En este sentido, el debate periodístico de La Libertad Católica con sus enemigos liberales fue permanente en sus páginas y se transformó en una efectiva demostración del compromiso profundo con las orientaciones pastorales de la autoridad eclesiástica y la formulación de un discurso legitimador de la guerra en virtud de la protección divina a la causa nacional. Por consiguiente, la Guerra del Pacífico se levantó como una inédita oportunidad para el pueblo católico penquista para demostrar el valor de la fe y su expresión bajo la protección por parte del "Dios de los Ejércitos". Por lo demás, la prensa católica no omitió en su discurso editorial la crítica a determinadas acciones gubernamentales que dañaron el mayoritariamente voluntario compromiso ciudadano frente a la guerra. Fue el caso de las comisiones de reclutamiento, su cuestionado accionar y la violencia utilizada muchas 
veces para incorporar forzosamente a integrantes del bajo pueblo a los regimientos que se movilizaron a los campos de batalla. En este sentido, la prensa de provincia se constituye en una extraordinaria fuente donde identificar la compleja dinámica del reclutamiento de soldados para el esfuerzo bélico nacional y la identificación de determinadas acciones de resistencia por parte de los sectores populares urbanos como rurales en el Chile profundo en el período 1879-1881.

En definitiva, la prensa regional -en especial la católica- desplegó discursos cohesionadores y homogeneizadores frente al esfuerzo bélico con el objetivo de orientar y legitimar determinados comportamientos sociales en aquellos sectores subalternos como las mujeres y los grupos populares, propiciando en la sociedad chilena lugares de encuentro frente a la amenaza externa que representó la Guerra del Pacífico. De esta manera se buscó superar, momentáneamente, las divisiones políticas, doctrinales y sociales que caracterizaron al Chile republicano de la segunda mitad del siglo XIX.

\section{Agradecimientos}

Agradecemos a Conicyt-Fondecyt por el respaldo económico para la presente investigación. Agradecemos los comentarios formulados al texto preliminar por parte de la profesora Gabriela Servín del Instituto de Investigaciones Históricas de la Universidad Michoacana de San Nicolás de Hidalgo (México).

\section{Referencias Citadas}

Aravena, L.

2004 El reclutamiento durante la Guerra del Pacífico 18791884. En Anuario de Difusión Histórica, 19.

Arellano, J.C.

2012 Discursos racistas en Chile y Perú durante la Guerra del Pacífico (1879-1884). En Estudios Ibero-Americanos, 38 (2), pp. 239-264.

Bonilla, $\mathrm{H}$

1974 Guano y burguesía en el Perú, IEP ediciones, Lima.

Bonilla, $\mathrm{H}$.

1980 Un siglo a la deriva. Ensayos sobre el Perú, Bolivia y la guerra, Instituto de Estudios Peruanos, Lima.

Cabrera, G. y Berbesí, L.

2006 Pensamiento moderno y opinión pública en Maracaibo (siglos XVIII-XIX). En Revista de Ciencias Sociales, 3, pp. 519-533.

Campos, F. 1980 Historia de Concepción, 1550-1970. Editorial Universitaria, Santiago.

Casanueva, $\mathrm{F}$.

2002 Prensa y periodismo en Concepción, 1833-2000. Escuela de Periodismo, Universidad Católica de la Santísima Concepción, Concepción.

Cavieres, E. y Aljovín, C. (comp.)

2005 Chile-Perú; Perú-Chile en el siglo XIX. Ediciones Universitarias de Valparaíso, Valparaíso.

Chaupis, J.

2007 (comp.) La Guerra del Pacífico. Aportes para Repensar su Historia. Vol. I, Fondo editorial de la UNMSM, Lima.

Chaupis, J.

2010 (comp.) La Guerra del Pacífico. Aportes para Repensar su Historia. Vol. II, Fondo editorial de la UNMSM, Lima.

Cid, G. y San Francisco, A.

2009 Nación y Nacionalismo en Chile. Siglo XIX-XX, Vol. 1-2. Centro de Estudios Bicentenario, Santiago.

Donoso, C. y Couyoumdjian, R.

2006 De soldado orgulloso a veterano indigente. La Guerra del Pacífico. En Historia de la vida privada, editado por R. Sagredo y C. Gazmuri, Taurus, Santiago.
Donoso, C. y Serrano, G. (edit.)

2011 Chile y la Guerra del Pacífico. Centro de Estudios Bicentenario, Santiago.

Fermandois, J.

2005 Mundo y fin de Mundo. Chile en la política mundial 1900-2004. Ediciones Universidad Católica de Chile, Santiago.

González, P.

1999 Literatura injuriosa y opinión pública en Santiago de Chile durante la primera mitad del siglo XIX. En Estudios Públicos, 76, pp. 233-262.

González, P.

2003 Sociabilidad y opinión pública en Buenos Aires (1821-

1852). En Historia Contemporánea (Universidad del País Vasco), 27, pp. 663-694.

Guerra, F.

1992 Modernidades e Independencias: ensayos sobre las revoluciones hispánicas, Mapfre, Madrid.

Guerra, F. y Lempériere, D. (comp.)

1998 Los espacios públicos en Iberoamérica. Ambigüedades y problemas. Siglos XVIII-XIX. Centro Francés de Estudios Mexicanos y Centroamericanos, Fondo de Cultura Económica, México.

Guerra, M.

1991 La Ocupación de Lima (1881-1883). El gobierno de García Calderón. Pontificia Universidad Católica del Perú. Instituto Riva-Agüero, Lima.

Guerra, M.

2004. La burguesía y la guerra con Chile. En La experiencia burguesa en el Perú (1840-1940). Editado por C. Mc Evoy, Iberoamericana, Madrid.

Habermas, J.

1986 Historia y crítica de la opinión pública, Gustavo Gilli, México.

Hodge, E. y Véliz, C.

2011 La infancia en el intersticio. Los niños chilenos combatientes en la Guerra del Pacífico (1879-1883). En Chile y la Guerra del Pacífico, editado por C. Donoso y G. Serrano, pp. 175-185. Centro de Estudios Bicentenario, Santiago. 
Home, D.

2007 Los huérfanos de la Guerra del Pacífico: El "Asilo de la Patria", 1879-1885. Centro de Investigaciones Diego Barros Arana-LOM Ediciones, Santiago.

Ibarra, $\mathrm{P}$

2013 Veteranos y prensa satírica: desmovilizados e inválidos en los periódicos chilenos de caricaturas durante la Guerra del Pacífico (1879-1884). En Universum, 28, 2, pp. 59-81.

Jaksic, I. y Serrano, S. 2010. El Gobierno y las libertades. La ruta del liberalismo chileno en el siglo XIX. En Estudios Públicos, 118, pp. 69-105.

Krebs, R.

1981 Catolicismo y laicismo. Seis estudios. Ediciones Nueva Universidad, Santiago.

Larraín, P.

2000 Las cantineras chilenas en la Guerra del Pacífico. Boletín de la Academia Chilena de la Historia, 110: 291-330.

Larraín, P.

2006. La presencia de la mujer chilena en la Guerra del Pacífico. Centro de Estudios Bicentenario, Universidad Gabriela Mistral, Santiago.

Manrique, N.

1981 Las guerrillas indígenas en la guerra con Chile. Centro de Investigación y Capacitación, Lima.

McEvoy, C.

2000 Bella Lima ya tiemblas llorosa del triunfante chileno en poder: una aproximación a los elementos de género en el discurso nacionalista chileno. En El Hechizo de las imágenes. Estatus social, género y etnicidad en la historia peruana, editado por N. Henríquez, pp. 197-222. Pontificia Universidad Católica del Perú, Lima.

McEvoy, C.

2006 De la mano de Dios. El nacionalismo católico chileno y la Guerra del Pacífico, 1879-1881. En Revista Bicentenario, 5, 1: 5-44.

McEvoy, C.

2007 ¿República nacional o república continental? El discurso republicano durante la Guerra del Pacífico, 1879-1884. En La República Peregrina. Hombres de armas y letras en América del Sur, 1800-1884, editado por C. Mc Evoy y A. Stuven, pp. 531-558. Instituto Francés de Estudios Andinos, Instituto de Estudios Peruanos, 2007, Lima.

McEvoy, C.

2009 Guerra, civilización e identidad nacional. Una aproximación al coleccionismo de Benjamín Vicuña Mackenna, 1879-1884. En Jahrbuch für Geschichte Lateinamerikas, 46, pp. 109-134.

McEvoy, C.

2010 Armas de persuasión masiva. Retórica y ritual en la Guerra del Pacífico. Centro de Estudios Bicentenario, Santiago.

McEvoy, C.

2011 Guerreros Civilizadores. Política, Sociedad y Cultura en Chile durante la Guerra del Pacífico. Ediciones Universidad Diego Portales, Santiago.

Medina, A.

1997 Mons. José Hipólito Salas. Universidad Católica de la Santísima Concepción, Concepción.

Méndez, C.

2004 Héroes del Silencio. Los Veteranos de la Guerra del Pacífico (1884-1924). Centro de Estudios Bicentenario, Santiago.
Méndez, C.

2009 Desiertos de Esperanza: de la gloria al abandono. Los veteranos chilenos y peruanos de la guerra del 79. Centro de Estudios Bicentenario, Santiago.

Méndez, C.

2013 Dolor y olvido. Los ex combatientes bolivianos de la Guerra del Pacífico. Centro de Estudios Bicentenario, Santiago.

Ortega, L.

1984 Los empresarios, la política y los orígenes de la guerra del Pacífico. FLACSO, Santiago.

Pacheco, A.

2003 Economía y sociedad de Concepción. Universidad de Concepción, Concepción.

Pinto, J.

1998 Cortar raíces, criar fama: El peonaje chileno en la fase inicial del ciclo salitrero (1850-1879). En Trabajos y rebeldías en la pampa salitrera, Editorial Universidad de Santiago.

Pinto, J., Valdivia, V. y Artaza, P

2003 Patria y clase en los albores de la identidad pampina (1860-1890). En Historia, 36, pp. 275-332.

Quiroz, A. y Gutiérrez, H.

1976 Dos soldados en la Guerra del Pacífico. Editorial Francisco de Aguirre, Buenos Aires.

Ravest, M.

1983 La compañía salitrera y la ocupación de Antofagasta 1878-1879. Editorial Andrés Bello, Santiago.

Rodríguez, A.

2001 Forjar y forzar identidades nacionales. El reclutamiento militar durante la Guerra del Pacífico en el mundo rural. En Pensamiento Crítico. Revista electrónica de Historia, 1.

Rodríguez, $\mathrm{S}$.

1985 Problemática del soldado durante la Guerra del Pacífico. Estado Mayor General del Ejército, Santiago.

Rubilar, M.

2004 Guerra y diplomacia: Las relaciones chileno-colombianas durante la guerra y postguerra del Pacífico 1879-1886. En Universum, 19, 1, pp. 148-175.

Rubilar, M.

2005 Chile, Colombia y Estados Unidos: Sus relaciones internacionales durante la Guerra del Pacífico y Posguerra del Pacífico 1879-1886. En Tzin-Tzun, 42, pp. 49-86.

Rubilar, M.

2011 Escritos por chilenos, para los chilenos y contra los peruanos: la prensa y el periodismo durante la Guerra del Pacífico, 1879-1883. En Chile y la Guerra del Pacífico, editado por C. Donoso y G. Serrano, pp. 39-74. Centro de Estudios Bicentenario, Santiago.

Rubilar, M.

2012 La política exterior de Chile durante la guerra y postguerra del Pacífico (1879-1891): las relaciones con Estados Unidos y Colombia. Diplomacia, opinión pública y poder naval. Tesis Doctoral, Universidad de Valladolid, Valladolid.

Santa Cruz, E.

1998 Conformación de espacios públicos masificación y surgimiento de la prensa Moderna en Chile siglo XIX. Centro de Investigaciones Sociales, Universidad Arcis, Santiago.

Santa Cruz, E.

2010 La prensa chilena en el siglo XIX. Patricios, letrados, burgueses y plebeyos. Editorial Universitaria, Santiago. 
Sater, W. 1986 Chile and the War of the Pacific. University of Nebraska Press, Lincoln.

Sater, W.

2005 La imagen heroica en Chile: Arturo Prat, santo secular. Centro de Estudios Bicentenario (la primera edición en inglés es del año 1973), Santiago.

Sater, W.

2007 Andean Tragedy. Fighting the war of the Pacific, 18791884, University of Nebraska Press, Lincoln.

Serrano, S.

2008 ¿Qué hacer con Dios en la República? Política y secularización en Chile (1845-1885). Fondo de Cultura Económica, Santiago.

Nota

José María Samper, "Rápida excursión por el centro y sur de Chile”, Buenos Aires, 9 de agosto de 1885.
Stuven, A.

2000 La seducción de un orden. Las élites y la construcción de Chile en las polémicas culturales y políticas del siglo XIX. Ediciones Universidad Católica de Chile, Santiago.

Tapia, C.

2009 Equilibrio de poder e influencia en las relaciones internacionales del Cono Sur: Chile y Ecuador, 1880-1902. En Estudios Avanzados, 12, pp. 151-167.

Toro, $\mathrm{P}$.

2011 Tiempo de guerra, tiempo escolar: vivencias de la Guerra del Pacífico en los liceos de hombres en Chile (1879-1883). En Chile y la Guerra del Pacífico, editado por C. Donoso y G. Serrano, pp. 25-37. Centro de Estudios Bicentenario, Santiago.

Publicado en el Periódico La Nación, Bogotá, 13-20 de octubre de 1885 . 
